\title{
Rhodium coated mirrors deposited by magnetron sputtering for fusion applications
}

L. Marot, G. De Temmerman, P. Oelhafen, G. Covarel, and A. Litnovsky

Citation: Review of Scientific Instruments 78, 103507 (2007);

View online: https://doi.org/10.1063/1.2800779

View Table of Contents: http://aip.scitation.org/toc/rsi/78/10

Published by the American Institute of Physics

\section{Articles you may be interested in}

Cleaning of first mirrors in ITER by means of radio frequency discharges

Review of Scientific Instruments 87, 11D439 (2016); 10.1063/1.4962055

Diagnostic first mirrors for burning plasma experiments (invited)

Review of Scientific Instruments 72, 475 (2001); 10.1063/1.1310580

Sputtering Yields at Very Low Bombarding Ion Energies

Journal of Applied Physics 33, 2345 (2004); 10.1063/1.1728959

Mirrorlike pulsed laser deposited tungsten thin film

Review of Scientific Instruments 82, 013101 (2011); 10.1063/1.3529441

Spectroscopic reflectometry of mirror surfaces during plasma exposure

Review of Scientific Instruments 83, 013509 (2012); 10.1063/1.3678640

Invited Article: Concepts and tools for the evaluation of measurement uncertainty

Review of Scientific Instruments 88, 011301 (2017); 10.1063/1.4974274

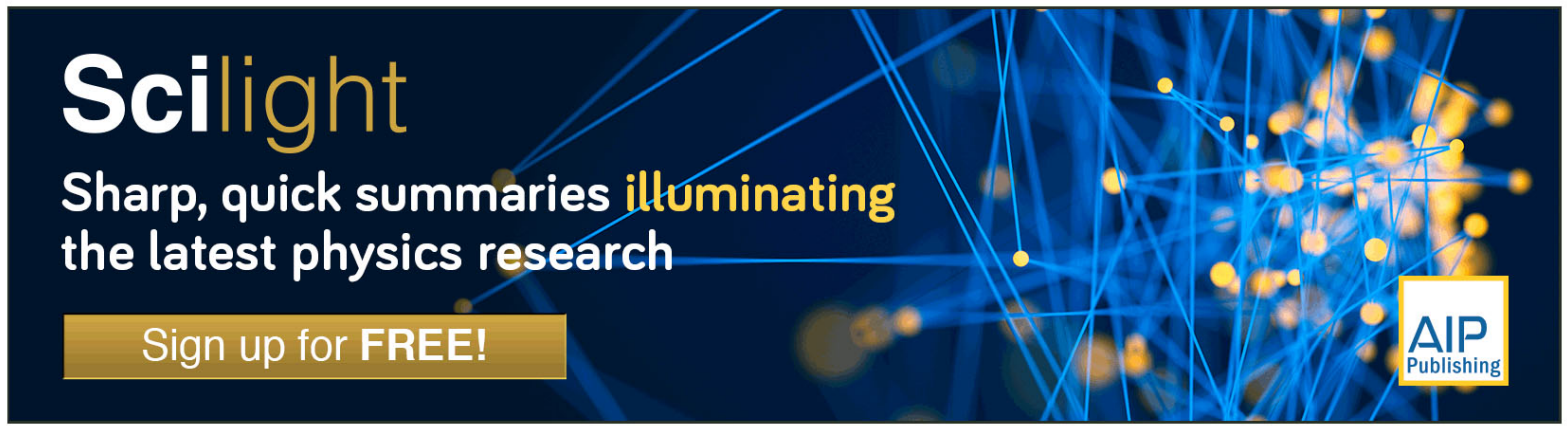




\title{
Rhodium coated mirrors deposited by magnetron sputtering for fusion applications
}

\author{
L. Marot, ${ }^{\text {a) }}$ G. De Temmerman, and P. Oelhafen \\ Department of Physics, University of Basel, Klingelbergstrasse 82, CH-4056 Basel, Switzerland \\ G. Covarel \\ Laboratoire Mécanique, Matériaux et Procédés de Fabrication, 61 rue Albert Camus, \\ Université de Haute-Alsace, F-68093 Mulhouse Cedex, France

\begin{abstract}
A. Litnovsky
Institut für Energieforschung (Plasmaphysik), Forschungszentrum Jülich, Association EURATOM-FZJ, D 52425 Jülich, Germany
\end{abstract}

(Received 19 July 2007; accepted 29 September 2007; published online 29 October 2007)

\begin{abstract}
Metallic mirrors will be essential components of all optical spectroscopy and imaging systems for ITER plasma diagnostics. Any change in the mirror performance, in particular, its reflectivity, due to erosion of the surface by charge exchange neutrals or deposition of impurities will influence the quality and reliability of the detected signals. Due to its high reflectivity in the visible wavelength range and its low sputtering yield, rhodium appears as an attractive material for first mirrors in ITER. However, the very high price of the raw material calls for using it in the form of a film deposited onto metallic substrates. The development of a reliable technique for the preparation of high reflectivity rhodium films is therefore of the highest importance. Rhodium layers with thicknesses of up to $2 \mu \mathrm{m}$ were produced on different substrates of interest (Mo, stainless steel, $\mathrm{Cu}$ ) by magnetron sputtering. Produced films exhibit a low roughness and crystallite size of about $10 \mathrm{~nm}$ with a dense columnar structure. No impurities were detected on the surface after deposition. Scratch tests demonstrate that adhesion properties increase with substrate hardness. Detailed optical characterizations of Rh-coated mirrors as well as results of erosion tests performed both under laboratory conditions and in the TEXTOR tokamak are presented in this paper. ( 2007 American Institute of Physics. [DOI: 10.1063/1.2800779]
\end{abstract}

\section{INTRODUCTION}

The first mirror is one of the most critical elements of the ITER diagnostic systems. It must survive in an extreme environment: intense UV and $\mathrm{x}$-ray radiations as well as particle fluxes due to charge exchange neutrals (CXNs) and has to maintain the required optical performance. ${ }^{1-3}$ Due to its high reflectivity in the visible wavelength range $(>70 \%-80 \%)$ and its low sputtering yield, rhodium may be a good candidate for first mirrors in ITER and is proposed as an option in the present design of ITER diagnostic systems such as LIDAR. ${ }^{4}$ However, there is a lack of experiments with mirrors made from this material. Single crystal molybdenum is currently the main candidate ${ }^{5}$ for first mirror material owing to its low sputtering yield and acceptable reflectivity. ${ }^{6}$ However, the feasibility of single crystal molybdenum mirrors with ITER-relevant dimensions is still yet to be demonstrated. Another way is to deposit Mo by magnetron sputtering on a metallic substrate. ${ }^{7}$ These films have the typical columnar structure for magnetron sputtering deposition, and we will see that our rhodium films are similar to those presented in Refs. 2 and 7. Figure 1 shows the spectral

\footnotetext{
a) Author to whom correspondence should be addressed. Present address: Department of Physics, Klingelbergstrasse 82, CH-4056 Basel, Switzerland. Electronic mail: laurent.marot@unibas.ch
}

reflectance calculated with optical constants given in Ref. 8 of various metals. The advantage of rhodium is obvious in the visible wavelength range in comparison to Mo or W; at $800 \mathrm{~nm}$ the reflectivities of $\mathrm{Rh}, \mathrm{Mo}$, and $\mathrm{W}$ are $82 \%$, $56 \%$, and $50 \%$, respectively. Rhodium has also good thermal properties (high damage threshold fluence: $F_{\text {th }}$ for thermomechanical stresses ${ }^{9}$ ) and a low sputtering yield $(Y)$. For example with $\mathrm{D}^{+}$at $300 \mathrm{eV}, \mathrm{Y}$ of $\mathrm{Cu}$ and $\mathrm{Al}$ is eight and six times higher as $\mathrm{Y}$ of $\mathrm{Rh}$, respectively. ${ }^{10}$

The high cost of rhodium as a raw material and rather large dimensions of mirrors needed for ITER (Ref. 4) lead to envisage its use as a deposited film on a suitably chosen metal. Such film has to have a small grain structure to limit the surface roughening due to erosion by charge exchange neutrals and a high adhesion to the substrate. Among existing techniques, two ways of preparing such mirrors have been explored: the first one is to deposit the $\mathrm{Rh}$ by magnetron sputtering, ${ }^{11}$ while the second one consists in applying the chemical and electroplating depositions of rhodium film onto substrate. ${ }^{12,13}$ No subsequent polishing after the Rh film deposition by magnetron is necessary, which has the advantage of simplifying the mirror preparation process in comparison to electrodeposition. In this work we will focus especially on optical properties of rhodium films deposited by magnetron sputtering on metallic substrates and the behavior of these layers in deuterium plasma under erosion conditions. 


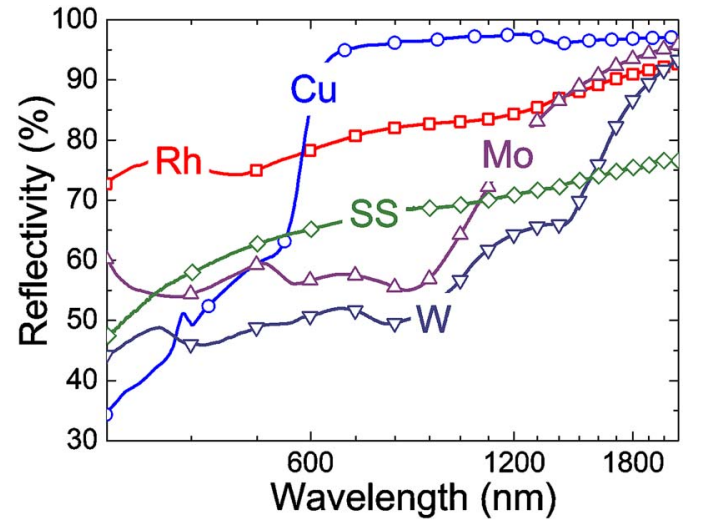

FIG. 1. (Color online) Spectral reflectance of $\mathrm{Rh}, \mathrm{Cu}, \mathrm{Mo}$, stainless steel (SS), and W calculated with optical constants given by Palik (Ref. 8) and commonly used as a reference.

\section{EXPERIMENTAL}

Deposition of rhodium was performed in a high vacuum chamber pumped down to a base pressure of about $2 \times 10^{-4} \mathrm{~Pa}$ using a conventional pumping system. Rhodium layers are deposited by magnetron sputtering with argon as a process gas on metallic substrates at a working pressure of $0.6 \mathrm{~Pa}$, for an electrical power of $25 \mathrm{~W}$ applied to the target (pulsed dc power supply) and room temperature (RT). Before deposition, the metallic substrates (stainless steel 304L, molybdenum, and copper) were polished first by abrasive $\mathrm{SiC}$ paper, then by diamond paste, and finally by an alumina powder of $0.05 \mu \mathrm{m}$ particle size to achieve a roughness $\left(R_{a}\right)$ ranging from 4 to $12 \mathrm{~nm}$ depending on the material. Sample surfaces were cleaned in situ before deposition with hydrogen plasma for $15 \mathrm{~min}$. A bias of $-50 \mathrm{~V}$ was applied on the substrates in order to remove remaining surface contamination. The x-ray photoelectron spectroscopy (XPS) measurements were performed in an UHV chamber attached to the deposition chamber. The electron spectrometer was equipped with a hemispherical analyzer and an x-ray source $(\mathrm{Mg} K \alpha$ excitation, $h \nu=1253.6 \mathrm{eV}$ ) for core level spectroscopy. As reference for the electron binding energy calibration, the $\mathrm{Au}$ $4 f_{7 / 2}$ line of a gold sample was set to $84.0 \mathrm{eV}$. Morphology of the films has been investigated by top view scanning electron microscopy (SEM) Hitachi S-4800 field emission at $5 \mathrm{kV}$. Surface roughness $R_{a}$ (arithmetic average) was measured with a TENCOR model alpha-step 500 profilometer for a scan length of $1 \mathrm{~mm}$ and for five scans. Ex situ measurements of the total reflectivity were carried out using a UVvis-near infrared (NIR) spectrophotometer Varian Cary 5 equipped with a $110 \mathrm{~mm}$ diameter integrating sphere under nearly normal incidence $\left(3^{\circ} 20^{\prime}\right)$ in the wavelength range of $250-2500 \mathrm{~nm}$. The reflectivities of the sample for linearly polarized light were performed for the parallel $R_{p}$ and perpendicular $R_{s}$ components of the light vector in dependence on a wavelength $(300-2300 \mathrm{~nm})$ and on an angle of incidence with a spectral ellipsometer SENTECH S 850. The adhesion properties were evaluated using a CSM Micro Scratch instrument scratch tester. During the test, the applied load was progressively increased from 0 to $20 \mathrm{~N}$ at a rate of $10 \mathrm{~N} \mathrm{~min}^{-1}$ and the scratch length amounted to $10 \mathrm{~mm}$. Five

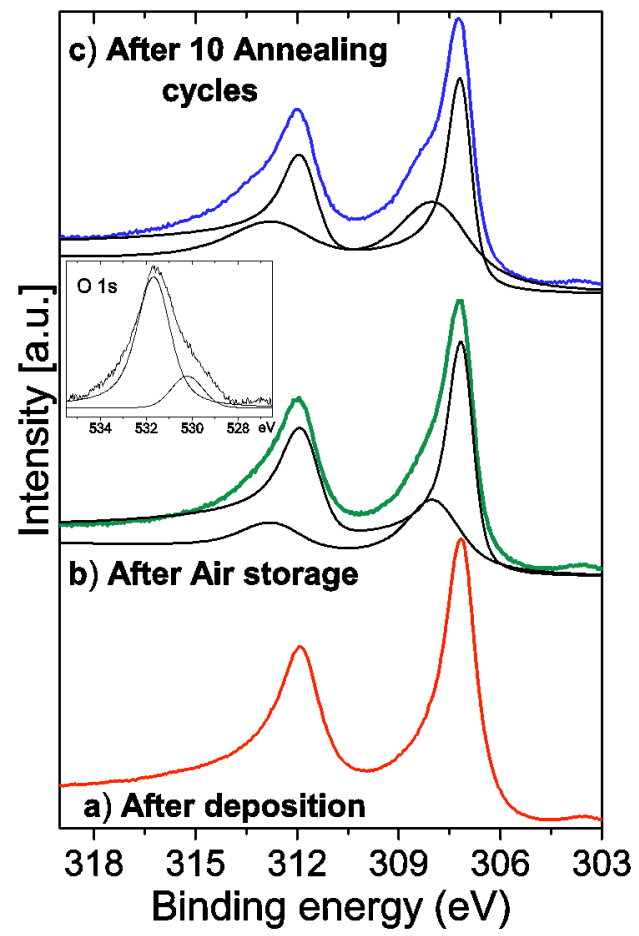

FIG. 2. (Color online) Rh $3 d$ doublet core level spectrum measured by XPS of rhodium film deposited on stainless steel without breaking the vacuum after deposition (a), after air storage (b), after tenfold annealing in air for $5 \mathrm{~h}$ at $200{ }^{\circ} \mathrm{C}$ (c). The inset is the plot of the $\mathrm{O} 1 s$ spectrum after air storage.

measurements were performed for each sample and an average value of the critical loads is obtained.

\section{CHARACTERIZATION OF DEPOSITED FILMS}

\section{A. Chemical analysis}

Detailed investigations of the influence of the deposition conditions on the properties of the films have already been presented in our previous paper. ${ }^{11}$ It is important to note that no impurities (oxygen, carbon, argon) were found in the films by XPS measurements carried out after deposition, whatever the deposition conditions. Figure 2(a) shows typical Rh $3 d$ core level spectrum obtained by in situ XPS measurements for a rhodium layer deposited on stainless steel. A fit procedure, using Doniach-Sunic functions ${ }^{14}$ was applied, after a Shirley background subtraction, ${ }^{15}$ reveals only one component of the $\mathrm{Rh} 3 d_{5 / 2}$ line at a binding energy of $307.0 \mathrm{eV}$ and a spin-orbit splitting of $4.6 \mathrm{eV} .{ }^{11}$

After long term storage in air, surface is covered with adsorbed molecules (oxygen, carbon) and a thin rhodium oxide layer is formed on the surface. The measured $\mathrm{Rh} 3 d$ spectrum [Fig. 2(b)] can be deconvoluted into two components at binding energies of 307.1 and $308.0 \mathrm{eV}$ and spinorbit splittings of 4.6 and $4.8 \mathrm{eV}$, respectively. The oxygen peak has also two components at 530.2 and $531.6 \mathrm{eV}$ (inset of Fig. 2), respectively. The former can be attributed to oxygen in direct bonding to the metal and assigned to $\mathrm{Rh}^{3+}$ $(308.0 \mathrm{eV}),{ }^{16}$ while the latter can be ascribed $\mathrm{OH}$ or $\mathrm{H}_{2} \mathrm{O}$ molecules adsorbed on the surface. ${ }^{16}$ For all the samples used in this study, no variation of the optical reflectivity was 


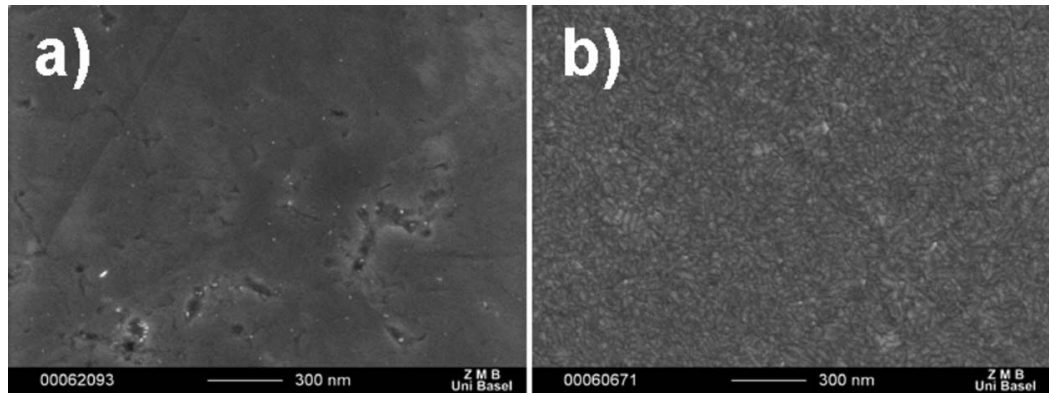

FIG. 3. SEM images of a rhodium film (b) $(1.8 \mu \mathrm{m}$ thick) deposited on molybdenum substrate (a). Before and after deposition, the surface roughness measured by profilometer is around $R_{a} \sim 4 \mathrm{~nm}$ and the crystallite size is $9 \mathrm{~nm}$ (Ref. 11).

observed after long air storage of the samples in contrary of molybdenum mirrors, ${ }^{5}$ showing advantageous properties of this material.

\section{B. Roughness after deposition}

The roughness of the film is an important issue for mirrors because of the associated loss of specular reflectance $\left(R_{\text {spec }}=R_{\text {tot }}-R_{\text {diff }}\right)$. After deposition, no further polishing of the samples was made, and yet very low roughness values were obtained. Figure 3(b) shows SEM image of a thick film $(1.8 \mu \mathrm{m})$ deposited on molybdenum substrate [Fig. 3(a)]. No change of the roughness was observed before and after deposition $\left(R_{a} \sim 4 \mathrm{~nm}\right)$. In this case the diffuse reflectivity measured is under $1 \%$ in the range of $250-2500 \mathrm{~nm}$.

A way to decrease the roughness after deposition, as described by Thompson, ${ }^{17}$ is to increase the mobility of atoms during deposition by increasing the temperature of a sample. In our case, three substrate temperatures: RT, 170, and $350{ }^{\circ} \mathrm{C}$ were investigated. Depositions of rhodium were done in the same conditions on clean stainless steel substrates with a constant film thickness of about $200 \mathrm{~nm}$. The roughness after deposition is indeed found to decrease with increasing substrate temperatures. This is shown in the inset of Fig. 4 where the ratio of the roughness values measured after and before deposition is plotted. Similar observations were made for deposition on silicon substrates. ${ }^{11}$ The specular reflectivity exhibits the similar behavior (Fig. 4) and increases by $1.6 \%$ and $2.1 \%$ for 170 and $350{ }^{\circ} \mathrm{C}$, respectively, at $400 \mathrm{~nm}$. All these measurements are similar to reference data.

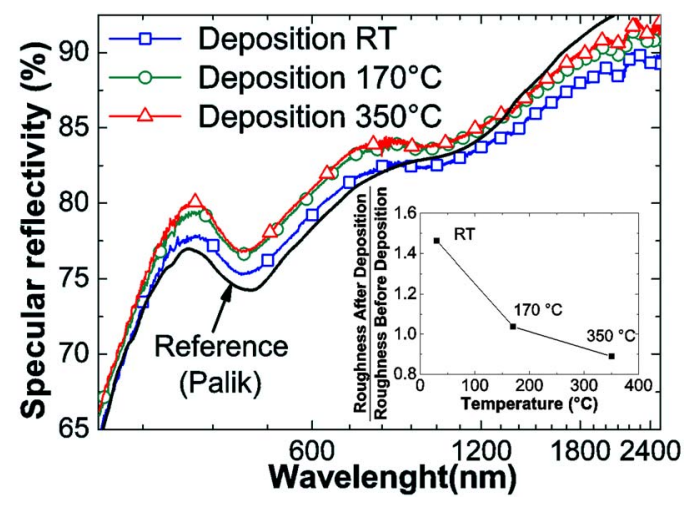

FIG. 4. (Color online) Specular reflectivity of the rhodium layer measured with a spectrophotometer for stainless steel substrates deposited at RT, $170{ }^{\circ} \mathrm{C}$, and $350{ }^{\circ} \mathrm{C}$. In the inset is plotted the ratio of the roughness after and before deposition against the deposition temperature. The reference curve is the reflectivity calculated with the data from Palik (Ref. 8).

\section{INFLUENCE OF THE SUBSTRATES}

\section{A. Optical characterizations}

To avoid thermal stress at the interface between a reflecting layer and the mirror substrate during laser exposition, the thickness of the layer should be much larger than the penetration depth of the heat wave. ${ }^{9}$ A thickness of at least several microns is needed to avoid this phenomenon and also to improve the resistance toward CXN erosion. For example, the maximum erosion of molybdenum mirrors for motional Stark effect (MSE) diagnostic in 5 years of ITER operation is estimated to be around $1 \mu \mathrm{m} .{ }^{18}$ Due to the different sputtering yields of rhodium the erosion of rhodium mirror during the same period is estimated around $4 \mu \mathrm{m}$. Rhodium was deposited on stainless steel, copper, and molybdenum without any buffer layer to investigate the influence of the substrate. For all these layers the thickness is in a range of 1.2-1.9 $\mu \mathrm{m}$. The total reflectivity (not shown here) for these different substrates is comparable to reference data. As expected, no influence of the substrate is noticed on the optical reflectivity.

For some diagnostics the polarization of the linearly polarized laser radiation is important. For example, in the case of MSE the incident laser radiation will be $s$ polarized. Reflectivity measurements were performed at incidence angles of $40^{\circ}, 50^{\circ}, 60^{\circ}, 70^{\circ}$, and $80^{\circ}$, for $s$ and $p$ polarized lights, and are plotted for a wavelength of $660 \mathrm{~nm}$ in Fig. 5. For a high incidence angle the $s$ component of rhodium mirror, similarly to what is observed for other metals, has a higher reflectivity than $p$ component. The dotted lines in Fig. 5 rep-

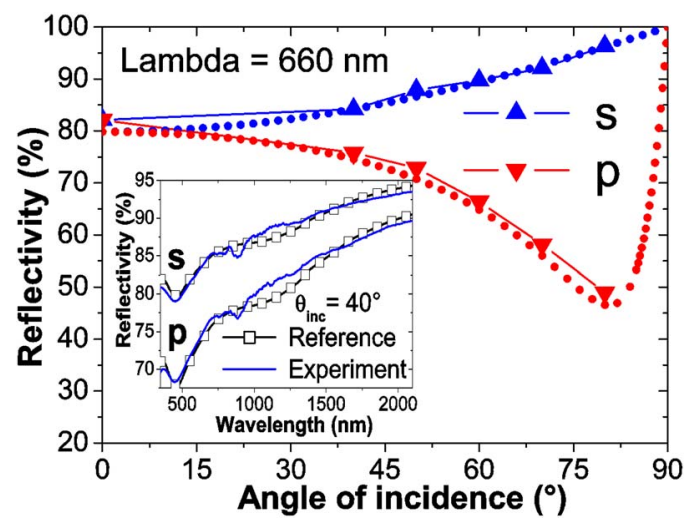

FIG. 5. (Color online) Rhodium film reflectivities at $40^{\circ}, 50^{\circ}, 60^{\circ}, 70^{\circ}$, and $80^{\circ}$ for $s$ and $p$ polarizations at $660 \mathrm{~nm}$. The dotted lines represent the $s$ and $p$ components calculated with the data from Palik (Ref. 8). The reflectivity of this mirror measured at $40^{\circ}$ for $s$ and $p$ polarizations and the reference curves calculated with data from Palik (Ref. 8) are shown in the inset. 


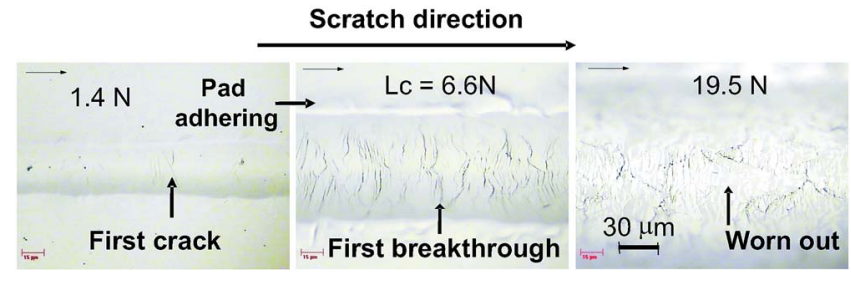

FIG. 6. (Color online) Main part of a scratch track on the rhodium film deposited at RT on stainless steel observed by optical microscope.

resent the $s$ and $p$ components calculated with the theoretical optical constants. The refractive index $(n)$ and absorption $\operatorname{index}(k)$ for this film are 2.05 and 5.71, respectively, at $660 \mathrm{~nm}$ in comparison to 2.22 and 5.81 from Ref. 19. In the inset of Fig. 6 the reflectivites of this mirror measured at $40^{\circ}$ for $s$ and $p$ polarizations and reference curves, calculated with the data from Palik, ${ }^{8}$ are plotted.

The optical characterizations described in this paper were done on the sample having $2 \mathrm{~cm}$ in diameter. One $\mathrm{Rh}$ layer was deposited on a square sample, $4 \mathrm{~cm}$ in size. The optical observations show a homogenous film on the whole surface. For mirrors with ITER-relevant sizes, the size of the magnetron target will of course have to be scaled up; however, from the observations made here, there are a priori no reasons for technological limitations in the preparation of larger samples.

\section{B. Effect of annealing cycles}

To investigate whether annealing cycles will have an effect on the mirror reflectivity and the thermal stresses between the reflecting layer and the mirror substrate, two mirrors were annealed ten times for $5 \mathrm{~h}$ at $200{ }^{\circ} \mathrm{C}$ in air. The rhodium layer thickness in both cases was $1 \mu \mathrm{m}$ thick and was deposited on stainless steel and on molybdenum. After the last annealing no evolutions of the total and the diffuse reflectivity are observed in the range of $250-2500 \mathrm{~nm}$. The optical observations did not reveal any modification or delamination of the layer. The XPS measurement after annealing cycles is quite similar to those made after air storage [Fig. 2(c)]. The spectrum has a more pronounced distinct shoulder for high binding energy side. After the fitting procedure described in Sec. III, this shoulder is found to be due to the $\mathrm{Rh}^{3+}$ component at $308.3 \mathrm{eV}$.

To investigate relevant ITER baking procedure, one sample $(1.7 \mu \mathrm{m})$ deposited on molybdenum was annealed for $6 \mathrm{~h}$ at $400{ }^{\circ} \mathrm{C}$ in vacuum $\left(1 \times 10^{-4} \mathrm{~Pa}\right)$. The observations after this treatment were similar as previously described, i.e., no change of the reflectivity, no delamination, and no surface modification.

\section{Adhesion of the coatings}

The adhesion strength is a complicated function of interface conditions, such as film thickness, film stress, surface roughness, and elastic properties of the substrate. ${ }^{20}$ Investigations of adhesion with the scratch-test method were carried out for a $200 \mathrm{~nm}$ thick rhodium coating deposited at RT on copper, molybdenum, and stainless steel substrates, respectively. The damage sequence observed for the steel substrate
TABLE I. Substrate hardness and rhodium layer critical load obtained after scratch test. SD: standard deviation.

\begin{tabular}{lcrrr}
\hline \hline Substrate & \multicolumn{2}{c}{$\begin{array}{l}\text { Hardness Vickers } \\
H_{V} 0.1 \text { and }(\mathrm{SD})\end{array}$} & \multicolumn{2}{c}{$\begin{array}{l}\text { Critical load } \\
(N)\end{array}$} \\
\hline Stainless Steel & 273 & $(15)$ & 6.6 & $(0.4)$ \\
Copper & 122 & $(2)$ & 1.5 & $(0.2)$ \\
Molybdenum & 261 & $(4)$ & 8.8 & $(0.8)$ \\
\hline \hline
\end{tabular}

is presented in Fig. 6. At an early stage of the scratch test, microcracking occurred in the track transversally to the scratch direction, indicating a cohesive failure within the layer. With increasing loading, the bending of the substrate induced its appearance under the cracks, while a pileup was progressively formed ahead of indenter. In addition, no wedge spallations were detected even at $20 \mathrm{~N}$; the coating presenting a rather good adhesion on the pileup. For all samples the failure mode appeared to be similar. Thus, the lowest load when the substrate was visible in the track was chosen as the critical load criterion. Measurements and the hardness of substrates, measured by a Vickers indentation method, are presented in Table I. The critical loads for rhodium on molybdenum and on stainless steel are comparable but five times higher than on copper substrate. For the failure mode described the adhesion properties increase with the substrate hardness. Such an increase of adhesion properties with the substrate hardness has already been observed in the case of other coatings on steels. ${ }^{21}$

More detailed results for adhesion properties of these films are described in Ref. 22. As described in Ref. 9 copper and stainless steel seem to be acceptable as substrate materials as far as distortion from heating is concerned. One criterion for making a choice between these two substrates could be the substrate hardness in order to improve the adhesion properties.

\section{EROSION OF RHODIUM MIRRORS IN LABORATORY EXPERIMENTS AND IN TOKAMAK}

\section{A. Evolution of the reflectivity after laboratory deuterium plasma}

The possible deterioration of mirror reflectivity as a result of erosion by CXN and redeposition of material eroded from plasma-facing components represents a serious concern for the reliability and long term usability of spectroscopic systems. As shown in Ref. 11 these films have no specific grain orientation and small grain size $(<15 \mathrm{~nm})$. In fact, it is more favorable to have no specific orientation for a polycrystalline material with small grain size to avoid surface roughening after erosion due to different sputtering yields of individual crystal planes. ${ }^{23}$ To test the behavior of rhodium mirrors in a deuterium plasma containing carbon impurities, experiments were carried out in the setup described in the experimental part. A deuterium glow discharge is created in the chamber by a hollow cathode covered by graphite, and a negative bias of $-300 \mathrm{~V}$ is applied to the mirror to control the impinging ion energy. Ion fluxes are determined by measuring the current passing through the sample, neglecting secondary electron emission. Details of this experiment can 


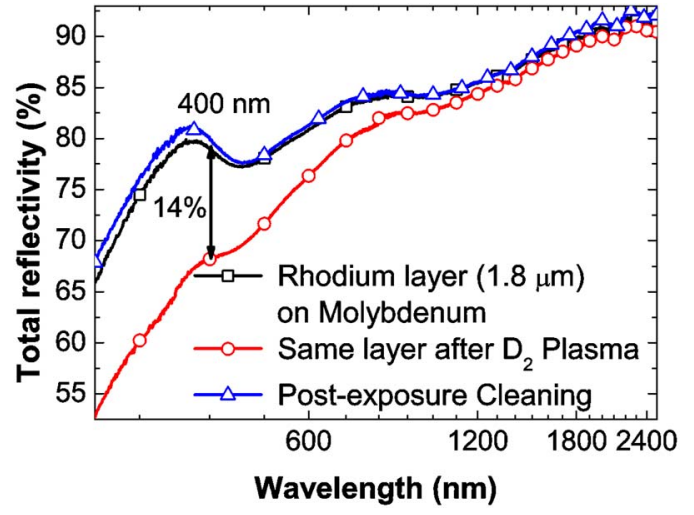

FIG. 7. (Color online) Total reflectivity of the rhodium layer, deposited on molybdenum, measured with a spectrophotometer before and after exposure to deuterium plasma and after postexposure cleaning.

be found in Ref. 24. A rhodium coated mirror, $1.8 \mu \mathrm{m}$ thick deposited on a molybdenum substrate, was exposed for $13 \mathrm{~h}$ to a deuterium plasma; the total accumulated fluence at the end of the exposure was $2 \times 10^{20}$ ions $\mathrm{cm}^{-2}$. This fluence corresponds to the $\mathrm{CXN}$ fluence onto the first mirrors in ITER accumulated during several hundreds of discharges. ${ }^{25}$ After plasma exposure, no significant evolution of the roughness and of the diffuse reflectivity was observed. In addition, surface SEM observations before and after this experiment did not reveal any change. From weight measurements of the mirrors before and after plasma exposure, it is possible to calculate the eroded thickness by the $300 \mathrm{eV}$ deuterium ions; for this fluence the eroded thickness was $375 \mathrm{~nm}$. In Fig. 7, the total reflectivities of the rhodium before and after exposure are plotted. As seen, a reflectivity decrease of $14 \%$ is measured at $400 \mathrm{~nm}$ caused by the deposition of a very thin carbon layer according to ex situ XPS measurements (not shown here). After deuterium bombardment, $32 \%$ of carbon and a small amount of oxygen on the surface are found. A deconvolution, as described in Sec. III, reveals only one component of the $\mathrm{C} 1 s$ line at $284.1 \mathrm{eV}$. This line is associated with a pure amorphous carbon phase coming from the coating of the hollow cathode, this position is consistent with the one reported by other authors. ${ }^{26}$ The presence of an amorphous carbon film explains the observed reflectivity decrease. A cleaning of this sample was carried out with hydrogen plasma for $30 \mathrm{~min}$. A bias of $-100 \mathrm{~V}$ was applied on the substrate in order to remove the amorphous carbon film. The temperature during this cleaning was $300^{\circ} \mathrm{C}$ to increase chemical erosion. The total reflectivity after cleaning as shown in Fig. 7 is comparable to that before the plasma exposure. We can conclude that after an eroded depth of $375 \mathrm{~nm}$ by deuterium plasma, the reflectivity was not affected by the physical sputtering of the surface. Two identical experiments have been performed on other rhodium layer deposited on stainless steel and copper. The same results have been obtained as described previously.

\section{B. Evolution of the reflectivity after exposure in TEXTOR}

An important issue for rhodium mirror foreseen for fusion applications is a test in a tokamak environment. Three

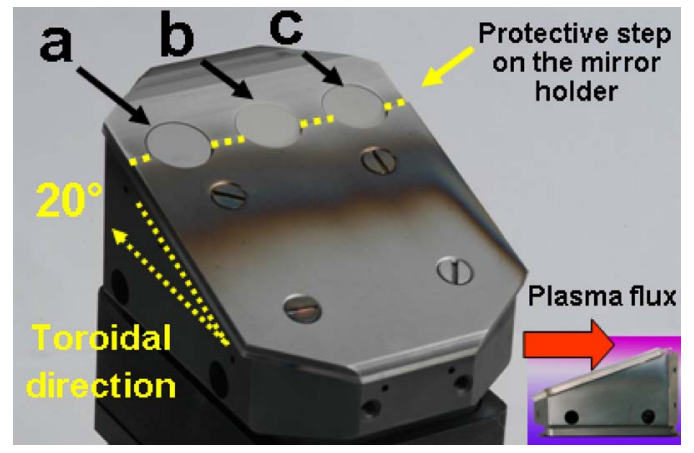

FIG. 8. (Color online) Holder with mirrors after exposure in the SOL plasma of TEXTOR. Single-crystal molybdenum mirror (a), rhodium mirror deposited by magnetron sputtering (b) (Ref. 11), and a rhodium mirror deposited by electrodeposition (c) (Ref. 12).

mirrors were exposed in the scrape-off layer (SOL) plasma of TEXTOR under erosion-dominated conditions in the same plasma environment. All three mirrors were placed in a row on the specially instrumented holder, made from TZM alloy consisting from $99 \% \mathrm{Mo}, 0.5 \% \mathrm{Ti}$, and $0.1 \% \mathrm{Zr}$. The holder with mirrors was inclined with an angle of $20^{\circ}$ with respect to the toroidal field direction like it is shown in Fig. 8. The leading edge of the holder was located at the radial distance of $R=47.3 \mathrm{~cm}$ from the plasma center, which corresponded to the distance of $\sim 13 \mathrm{~mm}$ from the last closed flux surface. 19 neutral beam injection (NBI)-heated identical plasma discharges were carried out with total plasma duration of $100 \mathrm{~s}$ with an averaged central electron density of $4 \times 10^{13} \mathrm{~cm}^{-3}$. The temperature of the bulk mirror holder was measured with thermocouples and was varying between 160 and $230{ }^{\circ} \mathrm{C}$ during the exposure. The surface temperature of the holders' plasma-closest leading edge rose up to $1200{ }^{\circ} \mathrm{C}$ during the discharge and the mirror temperature was within $300-500{ }^{\circ} \mathrm{C}$ as controlled with optical pyrometers. The energy of $\mathrm{D}^{+}$ions impinging the surface of mirrors was of order of $250 \mathrm{eV}$. The total fluence averaged was $3.41 \times 10^{20}$ ions $\mathrm{cm}^{-2}$, which corresponds to several hundreds of ITER discharges. ${ }^{25}$

The three exposed mirrors (Fig. 8) were single crystal molybdenum mirror (a), rhodium mirror deposited by electrodeposition (c), ${ }^{12}$ and a rhodium mirror deposited by magnetron sputtering (b). ${ }^{11}$ In the following only the results obtained for the latter will be described. Results for the other $\mathrm{Rh}$-coated mirror can be found in Ref. 27; the main changes found after the exposure are the decrease of the hemispherical reflectivity by $3 \%-10 \%$ and the modification of the mirror surface shape from flat to convex. The rhodium layer was deposited on a molybdenum substrate $(18 \mathrm{~mm}$ diameter) at room temperature and the thickness was $2.4 \mu \mathrm{m}$ as measured on witness-sample installed during the deposition process. The sample is shown in Fig. 8(b) and as an inset in Fig. 9. It kept its metallically shiny surface. However, small moonlike traces of deposition are present on the lower part of mirrors. These traces were artificially produced due to the plasma shadowing by the mirror holder having the protective "step" (Fig. 8), similarly as it was described by Litnovsky et al. The specular reflectivities measured in the middle of the mirror before and after exposure are shown in Fig. 9. After ex- 


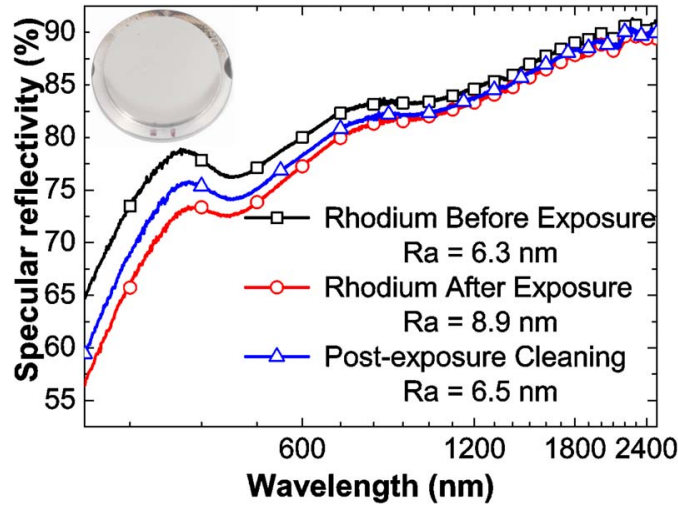

FIG. 9. (Color online) Photograph of rhodium mirror after exposure in TEXTOR. Specular reflectivity of the rhodium layer deposited on molybdenum, measured with a spectrophotometer before and after exposure in TEXTOR, and after postexposure cleaning procedure. The surface roughness $R_{a}$ indicated is measured by a profilometer.

posure, a slight decrease of the specular reflectivity is measured over the whole wavelength range. However, the most pronounced change appeared to be in the visible and ultraviolet wavelength ranges $(8 \%$ at $250 \mathrm{~nm})$. An increase of the diffuse reflectivity of about $0.5 \%$ is also measured over the whole wavelength range and the roughness $R_{a}$ increase from 6.3 to $8.9 \mathrm{~nm}$ after exposure. XPS and secondary ion mass spectroscopy measurements (not shown here) reveal the presence of a carbon film on the mirror surface. Traces of molybdenum and molybdenum oxide are also found on the surface, most likely due to the redeposition of material eroded from the sample holder made of molybdenum. The $\mathrm{Rh} 3 d$ spectrum is similar to that measured after air storage shown in Fig. 2(b). The crystalline grains appear much less distinctively on SEM observations after exposure.

Therefore the same cleaning procedure, as described in the previous section, of this sample was carried out with hydrogen plasma $\left(45 \mathrm{~min},-100 \mathrm{~V}, 300^{\circ} \mathrm{C}\right)$. The specular reflectivity after cleaning (Fig. 9) increases but did not reach completely the initial value.

The eroded rhodium thickness of the mirror has been estimated by making the crater through the Rh layer only using secondary ion mass spectrometry diagnostic (ION-ToF 4, FZJ, Germany) and then measuring the crater depth with stylus profiler Dektak 6M (FZJ, Germany), and is $440 \mathrm{~nm}$. The calculated sputtering yield $(Y)$ for the fluence of $3.41 \times 10^{20}$ ions $\mathrm{cm}^{-2}$ with this eroded thickness is $Y=0.009$. This value is higher than the $Y=0.006$ reported by Yamamura and Tawara, ${ }^{10}$ and also higher as the $Y=0.002$ for molybdenum at the same energy. Taking in account $2 \%-3 \%$ of sputtering carbon ions with two orders of magnitude higher sputter yield, this value is quite reasonable. Moreover, the eroded thickness calculated after this exposure is consistent to the one calculated for our laboratory experiment described in the previous part, which is $375 \mathrm{~nm}$ for $\mathrm{D}^{+}$at $300 \mathrm{eV}$ and a fluence of $2 \times 10^{20}$ ions $\mathrm{cm}^{-2}$.

\section{CONCLUSION}

In the present study we report various properties of rhodium coated metallic mirrors prepared by magnetron sputtering. No impurities were detected on the surface after deposition. The films have a low roughness and nanometersized crystallites with a dense columnar structure. Thick layers, more than $2 \mu \mathrm{m}$, exhibit very good optical reflectivity with a diffuse reflectivity lower than $1 \%$ over the UV-visNIR range. Storage of the samples in air did not affect the reflectivity. Nevertheless, the results of the scratch test performed in this study evidenced that adhesion properties increase with substrate hardness and are better for stainless steel and molybdenum. The first laboratory test of erosion by deuterium ions $(300 \mathrm{eV})$ and also annealing cycles are promising in view of diagnostic mirror applications. It is also important to note that the layer survived under erosion conditions in real tokamak (TEXTOR), although the reflectivity was decreased after exposure in tokamak plasmas. Further tokamak exposures are scheduled to understand this reflectivity decrease.

\section{ACKNOWLEDGMENTS}

The financial support of the Swiss Federal Office of Energy and of the Federal Office for Education and Science is gratefully acknowledged. The part of the work was supported by the European Fusion Development Agreement Contact No. TW5-TPDS-DIADEV. The authors would like to thank Roland Steiner for his help and Daniel Mathys.

${ }^{1}$ V. Voitsenya, A. Costley, V. Bandourko, A. Bardamid, V. Bondarenko, Y. Hirooka, S. Kasai, V. Konovalov, M. Nagatsu, K. Nakamura, D. Orlinskij, F. Orsitto, L. Poperenko, S. Solodovchenko, A. Stan, T. Sugie, M. Taniguchi, M. Vinnichenko, K. Vukolov, and S. Zvonkov, Rev. Sci. Instrum. 72, 475 (2001).

${ }^{2}$ A. Litnovsky, V. S. Voitsenya, A. Costley, and T. Donné, Nucl. Fusion 47, 833 (2007).

${ }^{3}$ A. Litnovsky, P. Wienhold, V. Philipps, G. Sergienko, O. Schmitz, A. Kirschner, A. Kreter, S. Droste, U. Samm, Ph. Mertens, A. H. Donné, D. Rudakov, S. Allen, R. Boivin, A. McLean, P. Stangeby, W. West, C. Wong, M. Lipa, B. Schunke, G. De Temmerman, R. Pitts, A. Costley, V. Voitsenya, K. Vukolov, P. Oelhafen, M. Rubel, and A. Romanyuk, J. Nucl. Mater. 363-365, 1395 (2007).

${ }^{4}$ M. J. Walsh, M. Beurskens, P. G. Carolan, M. Gilbert, R. B. Huxford, M. Loughlin, A. W. Morris, V. Riccardo, C. Walker, and Y. Xue, Rev. Sci. Instrum. 77, 10E525 (2006).

${ }^{5}$ A. Litnovsky, G. De Temmerman, K. Vukolov, P. Wienhold, V. Philipps, O. Schmitz, U. Samm, G. Sergienko, P. Oelhafen, M. Büttner, I. Orlovskiy, A. Yastrebkov, U. Breuer, and A. Scholl, Fusion Eng. Des. 82, 123 (2007).

${ }^{6}$ V. S. Voitsenya, V. I. Gritsyna, V. T. Gritsyna, V. G. Konovalov, D. V. Orlinskij, V. V. Ruzhitskij, and A. N. Shapoval, Fusion Eng. Des. 34-35, 365 (1997).

${ }^{7}$ A. Rogov and K. Vukolov, Tech. Phys. 51, 499 (2006).

${ }^{8}$ E. D. Palik, Handbook of Optical Constants of Solids (Academic, New York, 1985).

${ }^{9}$ L. de Kock, Design description document: Thomson scattering (core) LIDAR, ITER Document G 55 DDD 3 97-12-05 W 0.5 (1998).

${ }^{10}$ Y. Yamamura and H. Tawara, At. Data Nucl. Data Tables 62, 149 (1996).

${ }^{11}$ L. Marot, G. De Temmerman, V. Thommen, D. Mathys, and P. Oelhafen, "Characterization of magnetron sputtered rhodium films for reflective coatings," Surf. Coat. Technol. (in press).

${ }^{12}$ F. P. Orsitto, D. Del Bugaro, M. Di Fino, A. Maiolo, M. Montecchi, E. Nichelatti, C. Gowers, and P. Nielsen, Rev. Sci. Instrum. 72, 540 (2001).

${ }^{13}$ N. V. Klassen, S. I. Makhonin, and Yu. A. Osipyan, Materialovednie 2, 47 (1997) (in Russian).

${ }^{14}$ S. Doniach and M. Sunjic, J. Phys. C 3, 285 (1970).

${ }^{15}$ D. A. Shirley, Phys. Rev. B 5, 4709 (1972).

${ }^{16}$ A. A. Tolia, R. J. Smiley, W. N. Delgass, C. G. Takoudis, and M. J. Weaver, J. Catal. 150, 56 (1994).

${ }^{17}$ C. V. Thompson, Annu. Rev. Mater. Sci. 30, 159 (2000). 
${ }^{18}$ J. P. Allain, J. N. Brooks, and A. Hassanein, "ITER MSE Diagnostic First Mirror Analysis: Effects on Mirror Performance from Particle Irradiation," 12th Meeting of the ITPA Topical Group on Diagnostics, Princeton, N.J., 26-30 March 2007.

${ }^{19}$ J. H. Weaver, C. G. Olson, and D. W. Lynch, Phys. Rev. B 15, 4115 (1977).

${ }^{20}$ Y. Xie and H. M. Hawthorne, Surf. Coat. Technol. 141, 15 (2001).

${ }^{21}$ P. A. Steinmann and H. E. Hintermann, J. Vac. Sci. Technol. A 3, 2394 (1985).

${ }^{22}$ L. Marot, G. Covarel, M.-H. Tuilier, R. Steiner, and P. Oelhafen, "Adhesion of rhodium films on metallic substrates," Scr. Mater. (submitted).

${ }^{23}$ H. E. Rosendaal, Sputtering by Particle Bombardment I, Topics in Applied
Physics Vol. 47, edited by R. Behrisch (Springer, Berlin, 1981).

${ }^{24}$ G. De Temmerman, R. A. Pitts, V. S. Voitsenya, L. Marot, G. Veres, M. Maurer, and P. Oelhafen, J. Nucl. Mater. 363-365, 259 (2007).

${ }^{25}$ R. Behrisch, G. Federici, A. Kukushkin, and D. Reiter, J. Nucl. Mater. 313-316, 388 (2003).

${ }^{26}$ G. De Temmerman, M. Ley, J. Boudaden, and P. Oelhafen, J. Nucl. Mater. 337-339, 956 (2005).

${ }^{27}$ G. Maddaluno, M. Di Fino, F. Orsitto, A. Rufoloni, M. Montecchi, E. Nichelatti, E. Serra, A. Litnovsky, G. Sergienko, G. De Temmerman, and L. Marot, Proceedings of the 34th EPS Conference on Plasma Physics, Warsaw, Poland, 2007, No. P1-056 (unpublished). 